\title{
Polímeros no Espaço Sideral?
}

Este artigo sobre Titan é o primeiro publicado depois do "acordo de intercâmbio de artigos" firmado entre as duas organizações de polímeros brasileira e italiana (ABPol e AIM) conforme noticiado em nossa última edição sendo que o mesmo foi editado no AIM Magazine em Setembro de 2005.

Aparentemente parece ser um artigo totalmente fora da linha editorial da nossa Revista, mas seguramente faz parte da linha de artigos do AIM Magazine, e durante a leitura do mesmo o leitor descobrirá diversas conexões com os polímeros e com uma química especial desenvolvida no espaço profundo.

Tudo isso é decididamente interessante e o autor levou em especial consideração, a parte química destacando também a presença de polímeros na superfície do satélite de Saturno.

Interessantes são, para os cultivadores da ciência dos polímeros, as descrições das instrumentações tecnologicamente avançadas a bordo da Cassini e da Huygens, com o objetivo de efetuar análises sofisticadas em condições verdadeiramente críticas.

Além disso, as maravilhosas fotos, provenientes diretamente da NASA ou da ESA, contribuem para tornar o artigo ainda mais interessante.

No que diz respeito ao artigo original, publicado pela AIM, esse foi atualizado pelo mesmo autor, considerando também as futuras perspectivas.

\section{Abaixo das Nuvens de Titan}

Seis meses depois da entrada na órbita de Saturno $\left(1^{\circ}\right.$ Julho de 2004) a sonda Cassini desacoplou a cápsula HUYGENS na direção de Titan, o misterioso satélite coberto de uma impenetrável atmosfera, semelhante àquela da Terra primordial. A descida de HUYGENS nas nuvens de Titan (14 Janeiro 2005) desencadeou a formulação de uma série de sensacionais descobertas científicas. Aqui está uma síntese daquela aventura, focalizada principalmente sobre a parte química e geológica.

Em Março de 1656 Christian Huygens (1629-1695) publicou a obra "De Saturni luna observatio nova",

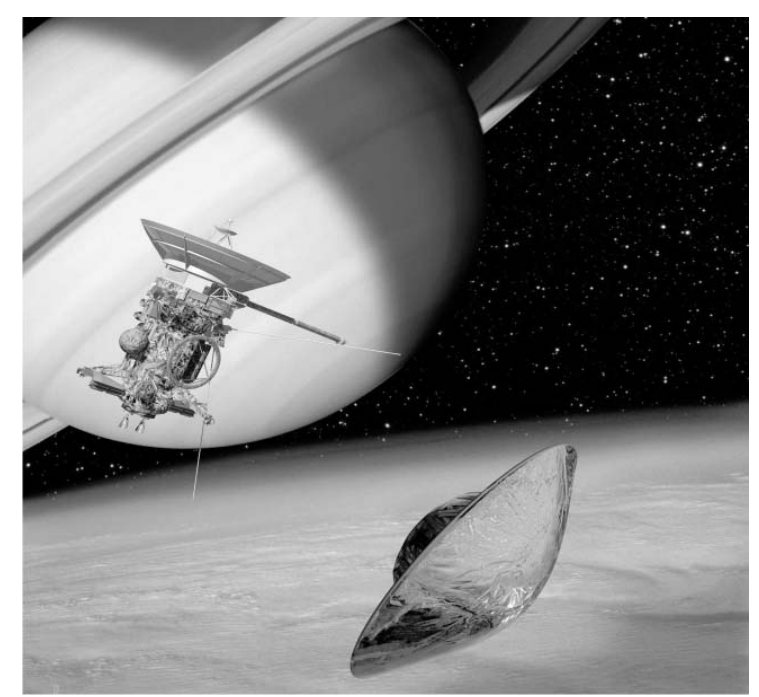

Figura 0. Uma fotomontagem que mostra contemporaneamente, na órbita de Saturno, a sonda Cassini, a cápsula Huygens que ela lançou na atmosfera do satélite Titan, que domina a parte baixa da fotografia mostrando a própria atmosfera cheia de hidrocarbonetos concernente à descoberta de Titan que ele fez em 25 de Março 1655, com um refrator de 35 centímetros que ele mesmo construíra com a ajuda do irmão Constantino. As primeiras medidas verdadeiramente acuradas do diâmetro foram obtidas somente três séculos depois, em 29 de março de 1974, com as medidas feitas por J. Veverka, com o refletor de 2.2 metros, de Mauna Kea, no Hawaii. Naquele dia Titan passou atrás da Lua no $1^{\circ}$ quarto e foi possível gravar fotometricamente a progressiva diminuição da luz. Foram medidas muito importantes porque forneceram a primeira verificação experimental do fato de que Titan era cercado por uma atmosfera de mais de $200 \mathrm{Km}$ de espessura: o que demonstrava um acentuado arredondamento inicial e final da curva de luz. Foi obtido um diâmetro global (satélite+atmosfera) de $5832 \pm 53 \mathrm{~km}$ e um diâmetro efetivo de cerca de $5400 \mathrm{~km}$. Tratava-se de um valor impreciso por excesso, que encontrou uma avaliação definitiva somente em Agosto em 1980, quando, com o Voyager-1, mediante medidas de ocultação rádio, foi definido um diâmetro preciso de $5120 \pm 52 \mathrm{~km}$. Portanto, Titan colocava-se em segundo lugar entre os satélites do sistema solar, superado em dimensões somente pelo Ganimede (diâmetro de $5280 \pm 30 \mathrm{~km}$ ), o maior satélite de Júpiter.

O mesmo Voyager-1, mediante medidas das perturbações induzidas por Titan à sua trajetória, forneceu uma avaliação da massa muito precisa de 0.0225 massas terrestres. Desta forma podia ser definitivamente calculada a densidade, cujo baixo valor $\left(1.9 \pm 0.06 \mathrm{~g} / \mathrm{cm}^{3}\right)$ nos obriga a admitir que quase $50 \%$ do total da massa do satélite é constituído de vários tipos de gelos.

É claro que tamanha fração gelada - comparada com aquela rochosa - deve ter influenciado enormemente a evolução geológica (passada e presente) do satélite. 
Relativamente à composição da atmosfera de Titan, os primeiros dados foram adquiridos no inverno de 1943-44 por G. Kuiper, no Observatório McDonald, por meio de um espectrógrafo conectado ao refletor de 2 metros (naquele tempo, o segundo no mundo em dimensões). Kuiper descobriu que os espectros de Titan eram dominados por duas bandas de absorção típicas do metano, uma no visível a 0.619 mícron e outra no infravermelho a 0.726 mícron. Por outro lado, a $6400 \AA$, o espectro de Titan dava a possibilidade de suspeitar da presença de amoníaco. Além disso, não se podia excluir (baseando-se em alguns modelos teóricos) a presença de alguns gases inertes (como Nitrogênio ou Argônio) não facilmente reveláveis espectrometricamente da Terra. Estes primeiros resultados espectroscópicos levaram logo a um grande interesse pelo estudo de Titan: era, de fato, o único corpo do sistema solar que tinha contemporaneamente uma superfície sólida e uma atmosfera redutora, exatamente aquilo que aconteceu na Terra nos primeiros dois bilhões de anos da sua evolução. As primeiras imagens avizinhadas da atmosfera titaniana foram gravadas em $1^{\circ}$ de Setembro de 1979 do Pioneer-11, que passou por perto do satélite, a cerca de $336000 \mathrm{~km}$. Foi deslumbrante constatar que se tratava de uma atmosfera muito densa e totalmente opaca, da qual saía continuamente um grande fluxo de Hidrogênio que tinha a tendência de distribuir-se ao longo de todo o plano orbital. Naquele momento foi difícil entender de onde era oriundo aquele Hidrogênio. Porém, uma coisa ficou logo bem clara: deveria existir uma ligação bem profunda e importante com a gênese global daquela extraordinária atmosfera.

No ano seguinte, em 12 de Novembro de 1980, foi a sonda Voyager-1 a efetuar o primeiro estreito "flyby" com Titan, a uma distância de $4000 \mathrm{~km}$. (Figura 1). A esperança era que essa distância fosse suficiente para obter, tanto imagens definidas da superfície, como espectros de alta resolução da atmosfera. Infelizmente a observação óptica da superfície mais uma vez foi uma desilusão (nenhuma partícula passou através da impenetrável capa de névoa avermelhada); diferentes resultados foram obtidos através das análises químico-físicas que reservaram enormes surpresas.

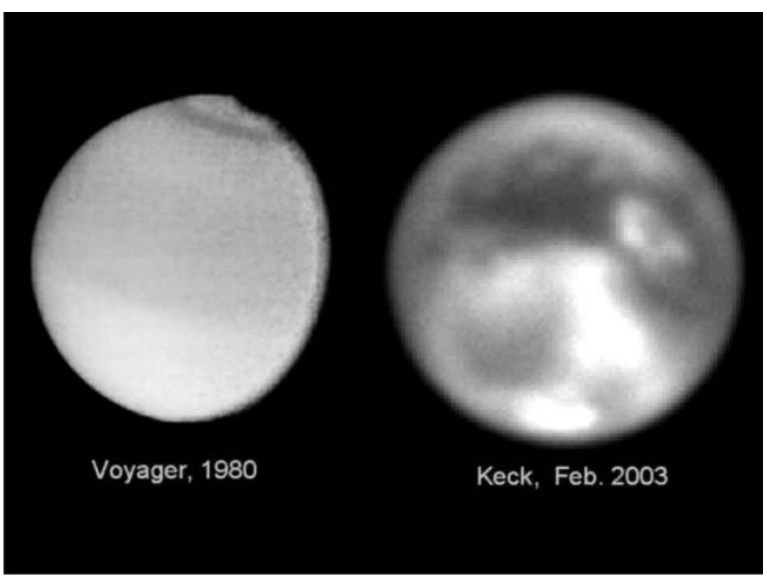

Figura 1. A atmosfera de Titan filmada no óptico do Voyager-1 em Novembro de 1980 de $4000 \mathrm{~km}$ de distância e a superfície filmada na banda do metano a 2.06 mícron, pelo telescópio Keck II em Fevereiro de 2003
O espectro no extremo UV, entre 800 e $1300 \AA$, gravado pelo Voyager-1 sobre o disco iluminado, além de confirmar uma perda contínua de Hidrogênio (emissão Ly $\alpha$ a $1216 \AA$ ), demonstrou que a atmosfera de Titan é dominada por muitas bandas de Nitrogênio molecular $\left(\mathrm{N}_{2}\right)$, excitado pelos elétrons da magneto-esfera de Saturno. É necessário dizer que, a surpresa não foi a descoberta do $\mathrm{N}_{2}$ (já dissemos que era teoricamente previsível), mas o fato que ele estivesse presente de forma maciça (pressão no solo de $1.5 \mathrm{~atm}$ ) como constituinte principal (mais de $90 \%$ no solo e mais de $99 \%$ na alta atmosfera). De importância semelhante, foi a determinação (com medidas de ocultação dos sinais rádio) de uma temperatura no solo verdadeiramente "glacial": $-180^{\circ} \mathrm{C}$ !

Para esclarecer a origem da atmosfera de Titan, é preciso considerar que na zona dos planetas gigantes, durante a formação do sistema solar houve um acúmulo de compostos reduzidos de Carbono e de Nitrogênio, em forma de $\mathrm{CH}_{4}$ (metano) e $\mathrm{NH}_{3}$ (amoníaco). Isto implica que a atmosfera de Titan deve ser, ou foi, muito rica de $\mathrm{NH}_{3}$ (capturada originariamente ou que se acumulou por causa da eliminação de gases do interior do satélite). Através da foto-dissociação, o $\mathrm{NH}_{3}$ deveria se transformar em $\mathrm{N}_{2}$ e $\mathrm{H}_{2}$, segundo a seguinte reação:

$$
2 \mathrm{NH}_{3} \rightleftharpoons \mathrm{N}_{2}+3 \mathrm{H}_{2}
$$

A coisa é aparentemente muito lógica, mas contrasta com a termodinâmica, porque a dissociação do $\mathrm{NH}_{3}$ é uma reação fortemente endotérmica, portanto é certamente desfavorecida num ambiente frio como aquele de Titan. Atualmente a hipótese mais aceitável é aquela da dissociação térmica de impacto, formulada por C.P. McKay (Ames Research Center) em 1988. McKay simulou o efeito de impactos meteóricos sobre Titan, submetendo várias misturas de $\mathrm{NH}_{3}+\mathrm{CH}_{4}$ a súbitos aquecimentos até $4000^{\circ} \mathrm{C}$, mediante impulsos laser. A análise por cromatografia gasosa dos produtos de reação evidenciou uma maciça formação de $\mathrm{N}_{2}$ e $\mathrm{H}_{2}$; porém, foi interessante descobrir também uma notável produção de $\mathrm{HCN} \mathrm{e} \mathrm{C}_{2} \mathrm{H}_{2}$, mais duas moléculas que, como precisaremos, são peculiares à atmosfera de Titan. É necessário acrescentar que, sendo a decomposição do amoníaco uma reação de equilíbrio, ela se favorece do fato de que o fraco campo gravitacional de Titan (cerca 1/10 daquele terrestre) não consegue manter o Hidrogênio que se forma durante a

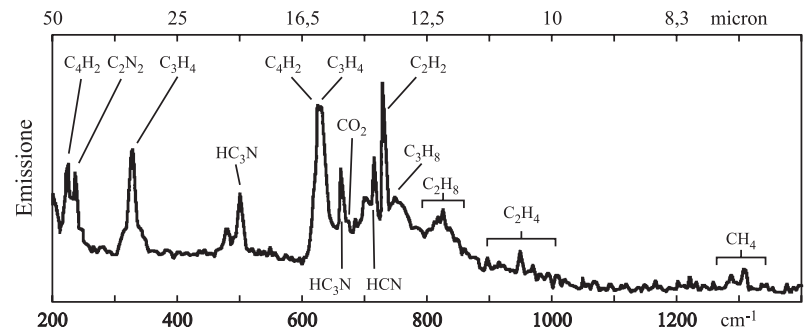

Figura 2. Em Novembro de 1980 o Voyager-I realizou o primeiro espectro infravermelho de alta resolução da atmosfera de Titan. Foram descobertos dezenas de hidrocarbonetos complexos e alguns derivados do ácido cianídrico: muitas dessas moléculas contribuíram em gerar sobre a Terra primordial as primeiras formas de vida. A sonda Cassini, a partir do Outono de 2004 confirmou substancialmente esses resultados 
reação. Os espectros infravermelhos, obtidos do Voyager-1, entre 7 e 50 mícron e durante uma dezena de horas a cavalo da máxima aproximação em 12 de Novembro de 1980, permitiram evidenciar, na alta atmosfera titaniana, a presença de uma complicada mistura de hidrocarbonetos saturados, insaturados e aromáticos, com um número máximo de 6 átomos de carbono. $\mathrm{O}$ composto dominante é o hidrocarboneto mais simples, ou seja, o $\mathrm{CH}_{4}$, cuja quantidade absoluta foi detectada entre 2-4\% (Figura 2).

Uma brilhante confirmação da presença dessas moléculas foi obtida em 26 de Outubro de 2004, pela instrumentação INMS (Íon and Neutral Mass Spectrometer), a bordo da sonda Cassini, durante o primeiro flyby aproximado com Titan (Titan A) a uma distância de $1200 \mathrm{~km}$.

O mecanismo mais plausível para formação desta mistura de hidrocarbonetos está ligado à decomposição do metano, sob o influxo da radiação ultra violeta solar ou das partículas de alta energia da magneto-esfera de Saturno, amplamente disponíveis na alta atmosfera de Titan.

Mesmo neste caso, é a liberação de $\mathrm{H}_{2}$ a favorecer o processo:

$$
\begin{aligned}
& 2 \mathrm{CH}_{4} \rightleftharpoons \mathrm{C}_{2} \mathrm{H}_{6}+\mathrm{H}_{2} \\
& 2 \mathrm{CH}_{4} \rightleftharpoons \mathrm{C}_{2} \mathrm{H}_{4}+2 \mathrm{H}_{2}
\end{aligned}
$$

De excepcional interesse, nos espectros obtidos do Voyager-1, foi a descoberta de uma absorção a $712 \mathrm{~cm}^{-1}(14$ mícron) atribuída à presença de $\mathrm{HCN}$. Foi a primeira vez que este composto era observado em uma atmosfera planetária e isso tinha um sentido não indiferente do ponto de vista exobiológico: os famosos experimentos executados por Miller nos anos 50 demonstraram, de fato, que nas condições redutoras da atmosfera primordial da Terra (extremamente semelhantes àquelas atuais de Titan), $\mathrm{CH}_{4}, \mathrm{NH}_{3}, \mathrm{H}_{2} \mathrm{O}$, na presença de fontes externas de energia (descargas elétricas, radioatividade, vulcanismo), ativaram a produção, inicialmente do $\mathrm{HCN}$ e depois saindo deste último, à formação de aminoácidos e bases nucléicas.

Relativamente às modalidades de formação do $\mathrm{HCN}$, podemos pensar em dois mecanismos alternativos (ambos, mais uma vez, favorecidos pelo desenvolvimento de $\mathrm{H}_{2}$ ).

Uma primeira possibilidade (ligada, sobretudo aos choques térmicos de impacto, postulados por McKay em 1988) é a reação direta entre metano e amoníaco:

$$
\mathrm{CH}_{4}+\mathrm{NH}_{3} \rightleftarrows \mathrm{HCN}+3 \mathrm{H}_{2}
$$

Uma segunda possibilidade é a reação direta do metano com o Nitrogênio (ao contrário, rigorosamente, com o $\mathrm{N}^{+}$, ou seja, o Nitrogênio ionizado que foi descoberto em grande quantidade na alta atmosfera):

$$
\mathrm{CH}_{4}+\mathrm{N}_{2} \rightleftharpoons 2 \mathrm{HCN}+3 \mathrm{H}_{2}
$$

Os espectros do Voyager-1 e da CASSINI evidenciaram também, junto com o $\mathrm{HCN}$, pequenas quantidades de cianogênio $(\mathrm{CN}-\mathrm{CN})$, cianoacetileno $\left(\mathrm{CN}-\mathrm{C}^{\circ} \mathrm{CH}\right)$, dicianoacetileno $\left(\mathrm{CN}-\mathrm{C}^{\circ} \mathrm{C}-\mathrm{CN}\right)$, cianeto de metila $\left(\mathrm{CH}_{3}-\mathrm{CN}\right)$.
É necessário dizer que a individualização espectroscópica de cerca de vinte moléculas orgânicas, das quais metade contém nitrogênio, aparece só como a "ponta do iceberg" em relação àquilo que está acontecendo na alta atmosfera de Titan. Foi possível entende-lo claramente, desenvolvendo em laboratório experimentos que submetiam misturas gasosas de $\mathrm{N}_{2}+\mathrm{CH}_{4}$ sob condições energéticas semelhantes (descargas elétricas, radiações UV, partículas de alta energia). O pioneiro desses estudos foi Carl Sagan, na Comell University no inicio dos anos 80 , ou seja, nos anos imediatamente subseqüentes às missões Voyager. Pesquisas análogas foram repetidas em seguida em muitos outros laboratórios e substancialmente confirmaram os resultados precedentes. Esses experimentos (sobretudo quando as fontes energéticas eram as partículas de alta energia) conseguiram reproduzir TODOS os compostos orgânicos descobertos em Titan (com a predominância de $\mathrm{HCN}$ entre os compostos nitrogenados e de $\mathrm{C}_{2} \mathrm{H}_{2}$ entre os hidrocarbonetos), ao mesmo tempo demonstraram que se formavam grandes quantidades de um material orgânico do tipo polimérico, muito difícil de ser individualizado por via espectroscópica. Tratava-se de uma mistura complexa de muitas moléculas diferentes na estrutura e no comprimento das cadeias, nas quais a presença de ligações simples e múltiplas entre os átomos de Carbono e de Nitrogênio gera uma coloração típica rubro alaranjada. Considerando que este tipo de material ainda não tinha uma denominação química, Carl Sagan inventou o termo "TOLINA", uma derivação do grego

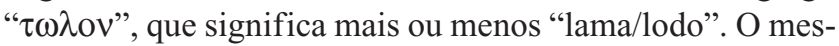
mo Sagan foi o primeiro a entender que este tipo de material, opaco e colorido, tinha uma ótima probabilidade de formarse na alta atmosfera de Titan (onde as fontes de energia externa eram mais vigorosas). O resultado das análises químicas foi deslumbrante. A tolina era uma mistura de uma centena de moléculas orgânicas, algumas dotadas de uma ação essencial na biologia terrestre, entre elas: purinas e pirimidinas (as bases do DNA), vários tipos de PHA (hidrocarbonetos aromáticos poli cíclicos) e muitos precursores de aminoácidos. Por exemplo: C. Sagan e B. Khare, em 1986, demonstraram que pelo menos $2 \%$ em massa de uma Tolina podia sofrer hidrólise ácida com a formação de algo como 16 aminoácidos em forma racema. A natureza da porção polimérica restante foi indagada a fundo por C. Sagan e P. Ehrenfreund, na metade da década de 90, emparelhando métodos pirolíticos e espectroscópicos. Saiu uma estrutura polimérica constituída de uma longa cadeia de átomos de Carbono e de Nitrogênio, na qual era a alternância entre ligações simples e duplas que justificava a intensa coloração escura. Um tear molecular apenas aparentemente inerte, pois violentos traumas térmicos em um ambiente úmido (do tipo do impacto de um meteorito sobre uma camada de tolina depositada sobre uma superfície gelada) podem favorecer a decomposição em aminoácidos e bases nucléicas.

Titan tornava-se, portanto, em todos os sentidos, um inacreditável laboratório natural no qual ficaram constantes, por bilhões de anos, condições químicas semelhantes àquelas que a Terra primordial experimentou há 4 bilhões de anos. 
A diferença está no fato de que na Terra a temperatura amena conservou a água na forma líquida e permitiu o avanço das reações químicas até resultar, ao final, nos seres viventes. Em Titan, ao contrário, a temperatura baixa demais teria sido um obstáculo insuperável sob dois pontos de vista: primeiramente impedindo a presença continuada de água líquida, depois, retardando as reações orgânicas a tal ponto que ficaram paradas no primeiro degrau (o seja no ácido cianídrico e na tolina). Mas não é este o ponto crucial: o que parece acontecer é que, quando em um ambiente químico criam-se as condições, mais cedo ou mais tarde algumas reações químicas acabam ocorrendo (estamos falando - vejam bem - de reações orgânicas e não da verdadeira vida) e é algo puramente episódico que em Titan as reações sejam extremamente retardadas por temperaturas demais baixas!

A tolina é um material pesado que, mesmo produzindose na atmosfera mais alta (onde são mais copiosas as fontes externas de energia), deveria continuamente cair sobre a superfície do satélite: é fácil prever que, depois de 4 bilhões de anos, a superfície de Titan deveria estar recoberta por uma imensa quantidade de lama orgânica, na ordem de centenas de metros, senão, quilômetros.

A verdadeira "máquina" que coloca em movimento toda a química atmosférica se encontra acima dos 400 quilômetros, onde a radiação ultravioleta solar fica suficientemente intensa para estimular a foto-reatividade do metano. Nesta região da luz invisível, umas imagens espetaculares gravadas da CASSINI em ultravioleta próximo, na ocasião do flyby em 13 de Dezembro de 2004, evidenciaram a presença de pelo menos uma dúzia de camadas concêntricas: mesmo sendo difícil dar para cada camada uma completa interpretação química, parece plausível pensar que se trata de compostos orgânicos derivados da foto-dissociação do metano que sedimentam a diferentes alturas, em função do próprio peso molecular, antes de se depositarem lentamente sobre a superfície (Figura 3).

É absolutamente improvável que qualquer forma de vida pode ter se desenvolvido neste imenso depósito de compos-

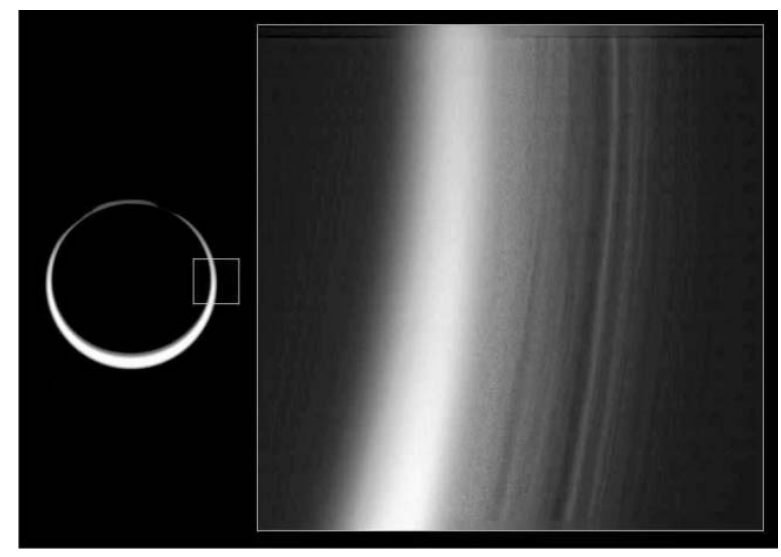

Figura 3. Esta espetacular imagem da alta atmosfera de Titan foi realizada em ultravioleta da sonda Cassini durante o fly-by de 13 de Dezembro de 2004. São visíveis pelo menos 12 camadas diferentes de material orgânico produzido através da decomposição do metano. É possível que as camadas sejam conectadas à presença de compostos de peso molecular cada vez maior tos carbônicos. Mas, num ambiente tão extremo e desconhecido nada pode ser considerado óbvio. Mesmo porque, num corpo gélido como Titan constituído por 50\% de água congelada, não é impossível imaginar nichos locais onde exista ou tenha existido água em forma líquida durante um tempo geologicamente apreciável. Se fosse assim, o contato entre a tolina superficial e a água líquida profunda, mesmo que episódico (atividade geológica, crio vulcanismo), poderia ter importantes conseqüências biológicas.

Uma fonte natural de água líquida poderia ser originada dos impactos meteóricos. Avalia-se, na base da craterização dos outros satélites de Saturno, que sobre Titan deveríamos encontrar cerca de 200 crateras de $20 \mathrm{~km}$ para cada milhão de $\mathrm{km}^{2}$ de superfície. O calor de um impacto asteróidico sobre uma superfície gelada gera uma quantidade de calor tão relevante que pode provocar imediata fusão do gelo e a formação de uma "bolha" de água líquida de dimensões pelo menos comparáveis àquelas da cratera. Segundo um trabalho de J. Rathbum (Lowell Observatory), publicado no início de 2002 a camada de gelo que logo se reformaria sobre a superfície do lago cratérico, bloquearia a perda total de calor, mantendo a água que está debaixo daquela camada protetora no estado líquido por dezenas de milhares de anos, e contemporaneamente, estimularia uma demorada atividade hidrotérmica. O propósito de J. Tathbum, na realidade, era procurar possíveis fontes de água líquida em Marte. Transpor isso totalmente para o caso de Titan ficaria muito fácil e, querendo, muito fascinante: de fato, existe uma grande diferença entre um lago de água líquida produzida com um impacto meteórico sobre uma superfície marciana e uma análoga reserva de água líquida produzida sobre uma superfície como aquela de Titan, recoberta de centenas de metros por material orgânico pré-biológico.

\section{As chuvas de metano}

Segundo um estudo publicado em 1992 de O.B. Toon (Universidade do Colorado/Laboratory of Atmospheric and Space Science) o tempo máximo de residência nas alturas, das partículas da névoa fotoquímica (smog) está ao redor dos 1000 anos. A conseqüência primária desse fato é que, sendo o smog algo persistente, a sua formação deve renovar-se continuamente, a custas do $\mathrm{CH}_{4}$ atmosférico: isso significa que deve existir algum processo (atividade geológica?) que consequentemente renova o metano consumido. Diferentemente, como demonstrou D. Strobel (Naval Research Laboratory) em 1982, toda a quantidade de metano atualmente presente na atmosfera de Titan ( $2 \%$ em altitude, isto é, nas alturas e 5\% em superfície) deveria esgotar-se em cerca de 10 milhões de anos.

A presença de uma quantidade estável de metano influi pesadamente sobre os primeiros $50 \mathrm{~km}$ da atmosfera de Titan (poderíamos grosseiramente falar de troposfera) que se torna ao mesmo tempo transparente e centro de fenômenos meteorológicos muito complexos.

Ponto basilar é o regime superficial da temperatura e da pressão $\left(-180^{\circ} \mathrm{C}\right.$ e $\left.1,5 \mathrm{~atm}\right)$, muito próximo ao ponto triplo 


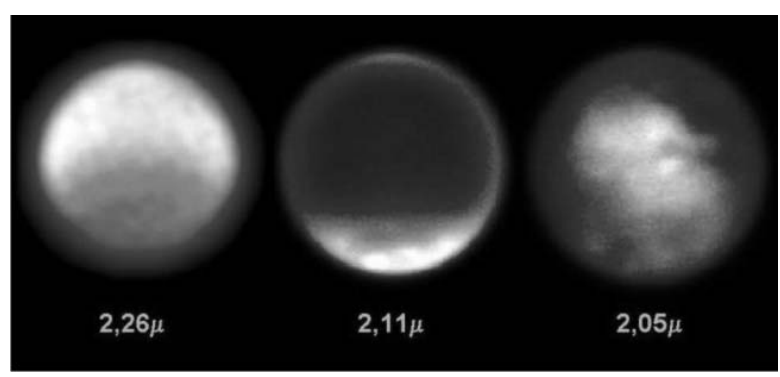

Figura 4. A estratosfera (à esquerda, a 2.28 mícron. Gemini Nord), a troposfera (no centro, a 2.11 mícron, Keck II) e a superfície (à direita, a 2.05 mícron, Keck II) de Titan, em imagens fotografadas em Dezembro de 2001 em comprimentos de ondas cada vez mais penetrantes. Nota-se: à esquerda uma nítida assimetria da luminosidade entre os dois hemisférios (produzida por causas naturais), no centro um complexo de nuvens na região polar sul. À direita, a marca do continente Xanadu

do metano: isso significa que este hidrocarboneto deveria estar presente no solo contemporaneamente nas três formas - líquida, sólida e gasosa - formando nuvens, chuvas e até mesmo lagos e rios.

É preciso ter in consideração que o estudo da baixa atmosfera de Titan, mesmo na superfície, é muito difícil devido ao efeito dominante da opacidade do smog fotoquímico. No início dos anos 90, W. Grundy (Lowell Observatory), encontrou uma maneira de resolver o problema, individualizando uma dezena de janelas muito finas, entre 0.5 e 5 mícron, através das quais o metano fica completamente transparente (0.830.94-1.07-1.28-1.59-2-2.9-4.8 mícron). O interessante é que, brincando estrategicamente no interior dessas janelas, foi possível fazer uma espécie de "tomografia" da troposfera de Titan, tendo sido possível decidir previamente o que fazer: alcançar a superfície ou parar a uma distância estabelecida, especialmente interessante. (Figura 4).

Em Novembro de 1997, um grupo de pesquisadores do Observatório de Paris, guiados por M. Combes e A. Coustenis, com o telescópio de 3.6 metros do ESO a La Silla (+ sistema de adaptação ADONIS - O sistema de adaptação é um sistema capaz de neutralizar a turbulência atmosférica conhecida pelos astrônomos com o têrmo "seeing") obteve as primeiras imagens da superfície de Titan, desfrutando da janela transparente de 2 mícron: nessas imagens o disco de Titan apareceu dominado por um "continente" claro, grande como a Austrália ("Xanadu") e disseminado de inexplicáveis manchas escuras, particularmente numerosas na faixa equatorial. Era a confirmação daquilo que já tinha intuído o Telescópio Espacial Hubble, em algumas imagens de Titan gravadas em Outubro de 1994 a 0.94 mícron. Foi necessário esperar até Fevereiro de 2004, para ter o primeiro mapa global da superfície de Titan: o mérito é da câmera com sistema de adaptação NACO, que, aplicada ao telescópio VLT YEPUN de 8.2 metros no cume do Cerro Paranal, trabalhou a 1.575 mícron, com o objetivo primário de dar uma olhada na região equatorial escura, onde, no ano seguinte deveria descer a cápsula HUYGENS. Era a primeira vez que Titan mostrava alguns detalhes da sua superfície, mas tratava-se de uma mistura de regiões claras (gelo descoberto?) e regiões escuras (acúmulo de tolina?) bem longe de uma possível compreensão.
Relativamente à confirmação da existência de uma fenomenologia atmosférica tão peculiar como a presença de nuvens e chuvas, foi necessário esperar até o início de 2002, quando foi publicada uma pesquisa realizada por Caitlin Griffith (uma planetóloga da Universidade da Arizona que beata ela - estuda Titan desde o início dos anos 90 com o telescópio Keck II de 10 metros, no Hawaii). A utilização de ópticas de adaptação permitiu alcançar a fantástica resolução de 0.01 ", isto é, a capacidade de distinguir detalhes de 100-200 km sobre um disco do diâmetro angular de somente 0.8 ": na prática, a placa de um carro a $100 \mathrm{~km}$ de distância... Mais uma vez foi decisiva a escolha correta do comprimento de onda. Escolheram a banda infravermelha de 2.11 mícron, porque se queria ter uma visão bastante nítida da troposfera titaniana entre $15-25 \mathrm{~km}$ de altura, ali onde precedentes investigações da mesma C. Griffith, evidenciaram traços indiretos de formações de nuvens. As maravilhosas imagens gravadas em 21 de Dezembro 2001, forneceram indícios muito sérios, não só da existência das nuvens, mas também das chuvas de metano. Nessas imagens a região polar sul de Titan mostrava uma meia dúzia de nuvens claras em movimento, das quais algumas se dissolveram em cerca de 1 a 2 horas: por isso, a idéia de que a causa daquela súbita dissolução fora repentinos e violentos 'aguaceiros'. Era a primeira vez que um ciclo nuvens-chuvas foi observado sobre um corpo planetário diferente da Terra.

Agora devemos perguntar se a existência de chuva pode significar uma eventual presença, sobre a superfície de Titan, de rios, lagos e talvez oceanos. Segundo os cálculos de J. Luinine (Caltech) a resposta seria sem dúvida positiva, mesmo sendo ainda não clara a verdadeira natureza química desses fluidos hidrocarbônicos. No entanto, parece excluída a existência, sobre Titan, de lagos de puro metano. De fato é preciso levar em consideração que com a atual temperatura de Titan $\left(-180^{\circ} \mathrm{C}\right)$ o metano não pode existir na forma líquida sem evaporar por si mesmo. Poderia manter-se em forma líquida se fosse 'poluído' por qualquer outro hidrocarboneto mais pesado: entre esses, o mais indiciado é seguramente o etano, o principal entre os seus produtos de decomposição.

Uma mistura constituída de $75 \%$ de etano, $20 \%$ de metano e $5 \%$ de nitrogênio é aquela que se adapta com mais exatidão às condições ambientais de Titan.

Acima dessa mistura fluida poderiam boiar icebergs de acetileno (o hidrocarboneto mais abundante além do etano) que é sólido nas condições ambientais da superfície de Titan.

Portanto, depois que as sondas Voyager nos tinham descrito Titan como um corpo misterioso e impenetrável, nos anos 80 , as novas tecnologias de observação dos anos 90 começaram a deixar-nos intuir interessantes novidades tanto do ponto de vista da morfologia superficial, como da dinâmica atmosférica.

Agora fica claro que, o fato de levar para perto de Titan sofisticadas instrumentações analíticas, seria uma ótima condição para tentar arrancar do satélite os seus segredos mais obscuros. O grande mérito da Missão Cassini foi aquele de fazer tudo isso e muito mais. 


\section{As primeiras descobertas da sonda Cassini}

A CASSINI foi lançada em 15 de Outubro 1997 com uma intenção bem clara: explorar em cada detalhe o sistema de Saturno por pelo menos quatro anos, desde a inserção orbital em $1^{\circ}$ Julho de 2004, e depois tentar descer uma pequena cápsula (HUYGENS) para Titan, a sua mais misteriosa lua.

A bordo da gigantesca sonda espacial foram colocados 12 instrumentos dotados de altíssimas características tecnológicas. Metade deles foi planejada para trabalhar em "remote sensing", ou seja, muito longe dos objetos a serem estudados (trata-se, obviamente, de todos os instrumentos capazes de gravar imagens e espectros). Uma outra metade foi planejada para funcionar "in situ", ou seja, bem no interior dos objetos a serem estudados (trata-se de sensores de pó, partículas com carga elétrica, campos magnéticos, etc.).

A antena de alta resolução HGA de 4 metros construída na Itália, merece uma menção especial. Além da tarefa de intercambiar com a Terra dados e imagens a alta velocidade, a HGA foi também planejada como RADAR, com a tarefa de perfurar as nuvens de Titan. Em 2 de Julho de 2004, poucas horas depois de sua ter entrada na órbita de Saturno, a CASSINI efetuou a primeira (TITAN 0) das 40 passagens (previstos em 4 anos) ao redor do pólo Sul de Titan, passando, todavia, a uma distância grande de $339000 \mathrm{~km}$. As informações adquiridas foram incrementadas e melhoradas durante os flyby muito aproximados $(1200 \mathrm{~km})$ em 26 de Outubro e em 13 de Dezembro de 2004, e foram muito importantes porque o objetivo principal deles era preparar a grande aventura da descida da cápsula HUYGENS (14 de Janeiro de 2005).

Naquela ocasião imediatamente confirmou-se a existência de nuvens de metano (Figura 5). O detalhe mais vistoso percebido através da CASSINI em 2 de Julho de 2004 sobre o pólo Sul de Titan foi, de fato, uma mancha clara, de pelo menos $500 \mathrm{~km}$, revelando-se nas imagens mais aproximadas, um espetacular complexo de nuvens menores, extremamente variáveis, tanto na forma como na posição. Era o único evento climático visível naquele momento sobre Titan, mas a sua presença foi decisiva. Da mesma forma, outras nuvens situadas a latitudes intermediárias foram encontradas através da CASSINI, durante muitos fly-by sucessivos, em 13 de Dezembro de 2004 (Titan B).

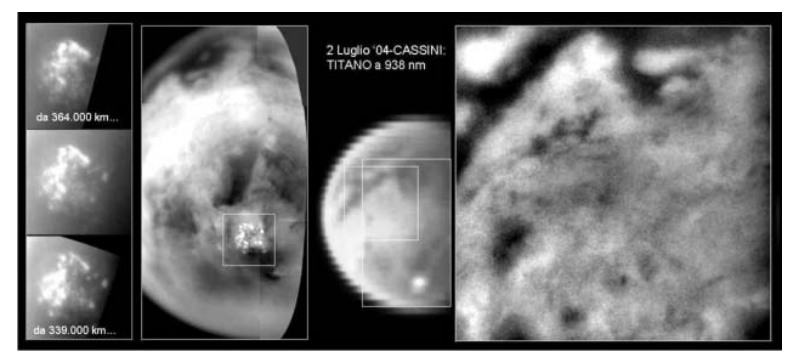

Figura 5. 2 de Julho de 2004: passando a $340000 \mathrm{~km}$ de Titan, o dia seguinte da entrada na órbita de Saturno, a Cassini conseguiu obter a primeiras imagens superficiais (janela do metano a 0.938 mícron) reveladoras de alguns detalhes. Entre as informações mais importantes, a demonstração da efetiva existência de nuvens de metano (esquerda) e a presença de enigmáticas formações superficiais (retilíneas ou circulares) tendo um fundo escuro (lagos de hidrocarbonetos?)
Relativamente à misteriosa natureza da superfície de Titan, a CASSINI perscrutou, em 2 de Julho de 2004, o hemisfério Sul utilizando a mais profunda (ou seja, a mais transparente) das bandas do metano, a de 0.938 mícron. Resultado: aumentaram as perplexidades e diminuíram as certezas! De fato, a superfície aparecia disseminada de enigmáticas formações arredondadas, com fundo escuro na direção das quais pareciam confluir sutis estruturas dendríticas, de comprimentos de até milhares de quilômetros. A absoluta ausência de reflexos solares intensos e repentinos parecia excluir a hipótese da presença de superfícies fluidas de hidrocarbonetos. Com essa situação cresceu excessivamente a espera dos dois fly-by de 26 de Outubro e de 13 de Dezembro de 2004, ambos programados para uma distância de apenas $1200 \mathrm{~km}$. Mesmo porque, pela primeira vez, a CASSINI tentaria transpassar as névoas de Titan com um radar sintético semelhante àquele com o qual a Magellano, no início dos anos 90, tinha mudado o rosto do planeta Vênus.

Tanto em 20 de Outubro, como em 13 de Dezembro de 2004, as imagens de Titan gravadas por CASSINI na janela do metano a 0.938 mícron, privilegiaram a região equatorial no Oeste do grande continente Xanadu, porque exatamente aí foi programada a descida da cápsula Huygens em 14 de Janeiro de 2005. As imagens, lindíssimas e muito nítidas, se apresentaram inicialmente incompreensíveis, pelo fato que nada de semelhante tinha sido visto sobre os outros corpos do sistema solar.

A constatação mais imediata foi a quase total ausência de crateras de impacto. Pois (como já tínhamos mencionado anteriormente) se calculava cerca de 200 crateras maiores que 20 $\mathrm{km}$ em uma superfície de um milhão de $\mathrm{km}^{2}$, ficou claro que a CASSINI tinha perscrutado uma superfície muito jovem do ponto de vista geológico. Os fatores que poderiam concorrer para rejuvenescer a superfície de Titan não são poucos. Alguns são de tipo meteorológico: por exemplo, o vento (cuja presença seria indicada pelos imponentes sistemas de estriamentos paralelos, sistematicamente dirigidos na direção Leste-Oeste), ou também as chuvas de metano, ou mesmo a contínua sedimentação da tolina estratosférica. O mais provável, porém, é que sejam fenômenos geológicos de crio vulcanismo que contribuem para rejuvenescer a superfície de Titan. Foram dois os fatores que puseram em movimento esta remonta de material frio (crio vulcanismo) para a superfície: uma é a excentricidade da órbita de Titan (0.0292) que, mesmo de origem desconhecida, é fonte de calor interno por interação de maré com Saturno; a outra é a existência de crio magma de gelo mais amoníaco, que pode manter uma fluidez semelhante àquela do magma de silicato terrestre, mesmo a temperaturas próximas de $-100^{\circ} \mathrm{C}$. Uma das técnicas utilizada pelo espectrômetro VIMS a bordo da CASSINI para discernir a presença deste crio magma, foi utilizar a janela atmosférica de 5.1 mícron, ideal para evidenciar "manchas térmicas". Uma dessas, estendida por $480 \mathrm{~km}$ em formato de uma estrutura de meia-lua, muito esquisita, foi visualizada durante ofly-by em 16 de Abril da distância de $1400 \mathrm{~km}$ (Figura 6). Se for ainda visível (talvez com mudanças de forma e dimensões) mesmo durante of fly-by 


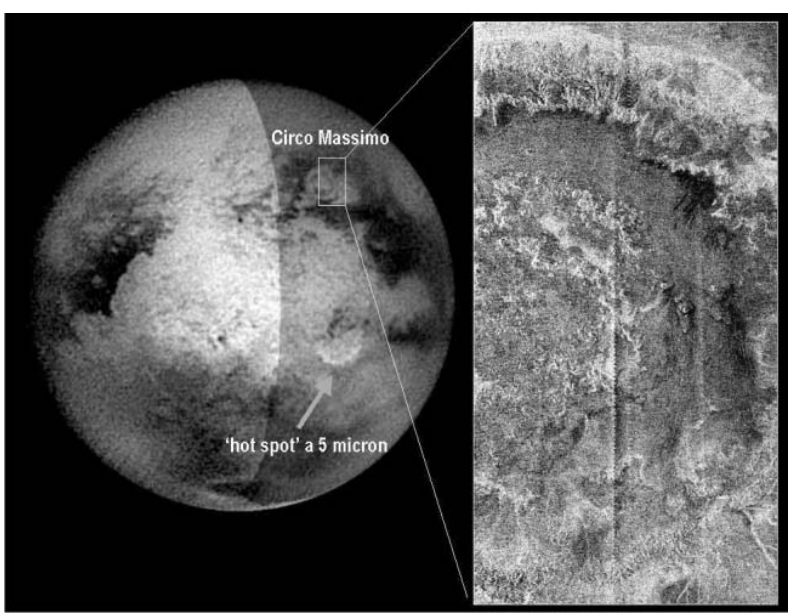

Figura 6. Uma imagem do hemisfério de Titan dirigida em direção de Saturno, obtida pela Cassini em 13 de Dezembro de 2004, a cerca um milhão de km de distância, à qual foi sobreposta uma outra de 5 mícron, fotografada em 16 de Abril de 2005. A grande "mancha térmica" (a maior dimensão quase alcança os $400 \mathrm{~km}$ ) evidenciada nas imagens a 5 mícron poderia ser uma região de crio vulcanismo ativo. Ao contrário, o radar da Cassini descobriu, em 15 de Fevereiro de 2005, que a estrutura circular mais para cima é uma impressionante cratera de $450 \mathrm{~km}$ de diâmetro (à direita)

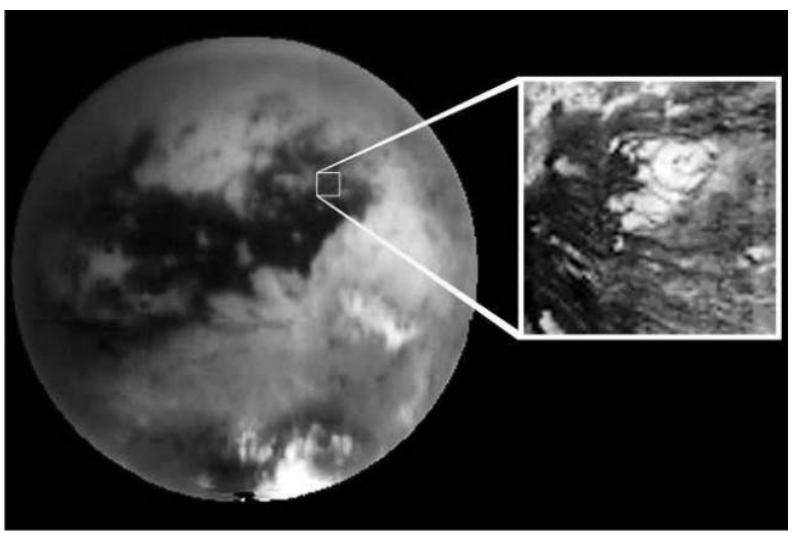

Figura 7. 26 de Outubro de 2004: um detalhe da superfície de Titan fotografado no interior da janela transparente do metano a 2 mícron, se evidencia uma estranha formação com camadas concêntricas que poderia ser indício de crio vulcanismo em evolução

NOTTURNO de 2 de Julho de 2006, a prova de que se trata de atividade endógena será inconfutável. Seguramente, depois de seis meses de estudos multi espectrais, a estranha estrutura de $30 \mathrm{~km}$ de diâmetro, descoberta durante o fly-by de 26 de Outubro de 2004, constituída por camadas concêntricas, sempre mais estreitas, parece que se pode interpretar como um vulcão em lenta erupção (Figura 7).

Ao que concerne à existência de lagos de hidrocarbonetos, a grande região escura descoberta no Oeste do continente Xanadu, pareceu muito suspeita: seus contornos com o terreno claro circundante eram tão nítidos que imediatamente lembravam o contato entre material fluido e material sólido. Sem ter em conta que o interior era disseminado por depósitos de material claro e esponjoso (hidrocarbonetos gelados?), e parecia uma reprodução exata de ilhas ou icebergs flutuantes.

Huygens deveria pousar em 14 de Janeiro de 2005 na extremidade ocidental desta espécie de "Mar Mediterrâneo

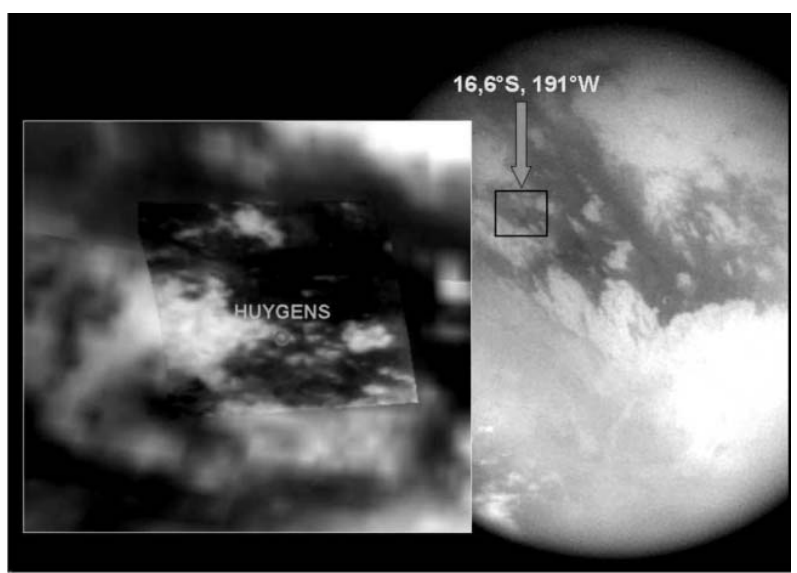

Figura 8. O lugar de pouso sobre Titan da cápsula Huygens, numa imagem de alta resolução, fotografada da Cassini em 26 de Outubro de 2004 a 0.938 mícron. O ponto de pouso fica no contorno entre um terreno claro e um terreno escuro: essa foi uma grande sorte porque permitiu entender imediatamente a natureza dos dois tipos de terrenos

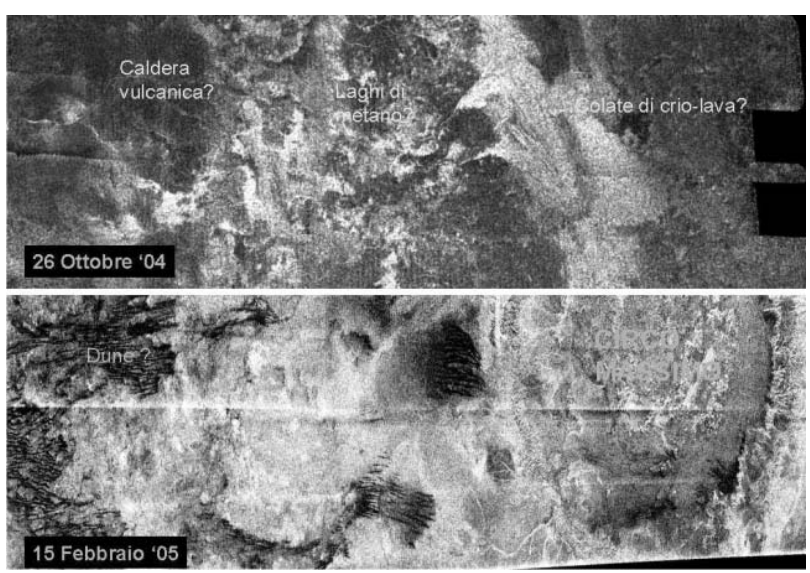

Figura 9. As primeiras imagens radar da superfície de Titan obtidas pela sonda Cassini durante os fly-by em 26 de Outubro de 2004 (fig.8). Entre os detalhes morfológicos mais interessantes, algumas prováveis emissões de crio lava, a possível presença de uma caldeira de cerca de $90 \mathrm{~km}$ e a descoberta de uma gigantesca cratera de impacto de $450 \mathrm{~km}$ (Circo máximo)

Titaniano", portanto em 13 de Dezembro de 2004 a CASSINI fotografou novamente a mesma zona com alta resolução, fazendo uma incrível constatação: o ponto onde HUYGENS deveria descer um mês depois estava exatamente entre um terreno claro e um terreno escuro (Figura 8). Como veremos depois, foi graças a esta afortunada casualidade que HUYGENS chegou a dissolver quase todos os mistérios de Titan.

Falávamos, entretanto, do fato de que, no fly-by em 26 de Outubro de 2004, a CASSINI perfurou pela primeira vez a atmosfera de Titan com o radar de microondas. Tratou-se de uma fenda larga com cerca de $200 \mathrm{~km}$, e longa com cerca de um milhar de quilômetros (Figura 9), que envolveu não mais de $1 \%$ da superfície, mas que por sua vez, forneceu informações importantes. A principal delas foi a confirmação de que a superfície de Titan deveria ser ainda ativa do ponto de vista geológico: essa atividade foi confirmada pela ausência das crateras de impacto, pela presença de extensas camadas de crio magma (brilhantes pela própria rugosidade e morfologicamente semelhantes às contrapartes de Vênus), 
pela descoberta de estruturas muito semelhantes a gigantescos edifícios vulcânicos. Nem sequer faltavam algumas manchas muito obscuras, que davam imediatamente a impressão de superfícies "pantanosas". Fenômenos análogos foram também evidenciados durante uma segunda investigação com radar, efetuada em 15 de Fevereiro de 2005. Nessa ocasião foram também descobertas sobre Titan as duas primeiras crateras, seguramente de impacto: uma delas, denominada Circo Máximo, tem um diâmetro de $450 \mathrm{~km}$, resultando, portanto, em uma das maiores do Sistema Solar.

Nesse ponto tudo estava pronto para que a vanguarda da missão passasse para a cápsula HUYGENS, esperada pelo menos há um quarto de século por uma geração inteira de cientistas.

\section{HUYGENS: missão cumprida!}

O "cordão umbilical" entre a HUYGENS e a CASSINI, desfez-se definitivamente às $3: 00 \mathrm{~h}$ da madrugada de 25 de Dezembro de 2004. Deste momento em diante, HUYGENS iniciou uma longa viagem que a teria levado para as nuvens de Titan depois de 22 dias, ou seja, em 14 de Janeiro de 2005. A bordo foram colocados seis instrumentos capazes de desvendar em todos os detalhes os mistérios da atmosfera e da superfície de Titan. As únicas fontes de energia eram duas baterias que, pelas estimativas, não poderiam funcionar mais de duas horas e meia: daí a necessidade de limitar a não mais de duas horas e meia o tempo da descida sobre a superfície de Titan. Três instrumentos eram posicionados diretamente no fundo da cápsula para ter imediato acesso ao ambiente externo. O primeiro era um GC-MS (Gas Chromatography Mass Spectrometer) que efetuou análises qualitativas e quantitativas de todos os componentes atmosféricos, compreendendo os isótopos. O segundo, denominado ACP (Aerosol Collector and Pyrolyser) recolheu com um filtro algumas amostras de aerosol tanto em grandes alturas $(125 \mathrm{~km})$ como muito próximo ao solo (entre 23 e $17 \mathrm{~km}$ ) e determinou a composição depois da combustão num adequado forno (Pyrolizer) e enviou-a para as análises ao GC-MS. A terceira instrumentação era a chamada SSP (Surface Sample Package). A sua primaria tarefa era a de avaliar as propriedades químicas e físicas da superfície do pouso (eram poucos aqueles que confiavam na sobrevivência da cápsula depois do pouso...). Mais duas instrumentações eram dedicadas totalmente por uma gravação em tempo real das principais propriedades físicas da atmosfera. Uma era a chamada DWE (Doppler Wind Experiment), capaz de medir qualquer influência mínima dos ventos locais sobre o Probe pelo deslocamento Doppler de um sinal radio ultra-estável enviado em continuidade sobre o Orbiter. A segunda, muito importante, era a HASI (ou seja, Huygens Atmospheric Structure Instrument) gerenciada pelo italiano Marcello Fulchignoni (Observatório de ParisMeudon) para determinar o perfil térmico, o andamento da pressão e, enfim, a presença de raios de temporal (sob forma de descargas elétricas ou de rumor acústico).

A sexta instrumentação do Probe era a DISR (Descent
Imager/Spectral Radiometer) cuja tarefa era a de adquirir imagens da superfície e realizar espectros UV até o IR próximo (0.3-1.6 mícron). Este trabalho foi realizado por três câmaras (uma horizontal de baixa resolução, uma vertical de alta resolução e dirigida para baixo e uma de média resolução com inclinação de $45^{\circ}$ ) que, graças à lenta rotação do Probe em volta do seu eixo, gravaram uma série de imagens panorâmicas de $360^{\circ}$. Todas as operações que o Probe efetuou nas nuvens de Titan foram pilotadas automaticamente desde sua ativação, efetuada pouco antes do desacoplamento da CASSINI do chamado MTU (Master Time Unit), um relógio interno de importância decisiva e que não podia absolutamente falhar (por isso existiam três copias idênticas a bordo).

Na manhã de 14 de Janeiro de 2005, o despertador do HUYGENS tocou muito cedo. De fato o MTU (ou seja, o timer de bordo) ativou todos os sistemas de bordo às 5:41:20 $\mathrm{h}$ (hora italiana). Às 10:06h (hora italiana) chegou o momento da verdade: HUYGENS mergulhou na alta atmosfera de Titan (1270 km de altitude) com uma velocidade de 22000 $\mathrm{km} / \mathrm{h}$ e foi refreando até $1200 \mathrm{~km} / \mathrm{h}$ em 3 minutos. O tremendo calor desenvolvido pelo atrito (mais de $1600^{\circ} \mathrm{C}$ ) foi neutralizado por um escudo anti térmico, constituído por uma estrutura do tipo favo mel de abelha, em fibra de carbono, recoberta por pequenas placas isolantes em fibra de silício. Exatamente às $11.20 \mathrm{~h}$ (hora italiana) o radiotelescópio de Green Bank (em Virgínia) seguido depois por outras 18 instrumentos análogos, chegou a captar o fraquíssimo sinal guia ultra-estável de 10 Watt, emitido da HUYGENS, com o único propósito de poder ser reconhecido. Era a primeira prova que a cápsula tinha superado o trauma da entrada na atmosfera titaniana e que estava funcionando regularmente.

Graças a sucessiva abertura dos três pára-quedas de dimensões progressivamente decrescentes (para neutralizar o aumento da densidade atmosférica) o impacto com o solo de Titan aconteceu a uma velocidade de $17 \mathrm{~km} / \mathrm{h}$ às 12:38:11h (hora italiana), depois de uma descida que durou um total de 2 horas 37 minutos e 50 segundos. Os dados que foram adquiridos pelos diversos instrumentos foram automaticamente e em tempo real, enviados ao micro do Orbiter (ou seja, da CASSINI, que por sua vez transitava a $60000 \mathrm{~km}$ acima do ponto de pouso). Depois das 17:00h (hora italiana), quando a conexão foi interrompida com HUYGENS, a CASSINI (mesmo com um problema técnico significativo, do qual não falaremos para ser breve) chegou a re-enviar à Terra a maioria dos dados recolhidos. Ninguém sabia sobre que tipo de terreno teria pousado HUYGENS (sólido, líquido). De uma coisa, porém, todos estavam convencidos: de que mesmo que os acontecimentos tivessem ocorrido do melhor jeito possível, a autonomia da bateria teria dado à sonda um tempo a mais de vida que não foi superior à poucos minutos. Inacreditavelmente as coisas foram muito melhores que as previsões mais otimistas: a CASSINI ficou em contato com HUYGENS por 72 minutos depois do pouso, adquirindo informações de inestimável valor científico. Os contatos foram forçadamente interrompidos somente depois do Orbiter pôr-se atrás do horizonte de Titan. Na realidade HUYGENS 
sobreviveu ainda por um bom tempo porque os radiotelescópios da Terra continuaram a captar o sinal guia durante quase 3 horas! As informações do penetrômetro a bordo da instrumentação SSP, permitiram entender como foi que HUYGENS pôde superar brilhantemente o trauma do impacto: o terreno onde pousou era macio e "lamacento", constituído de uma sutil crosta (pó de gelo mais material orgânico?) abaixo da qual a sonda afundou facilmente por uma quinzena de centímetros. Evidentemente tratava-se de um terreno "úmido", molhado recentemente por uma "chuva" abundante e insistente. Foi possível compreender graças a uma circunstância realmente afortunada: na prática o calor resultante do impacto da HUYGENS sobre o terreno gelado, produziu uma súbita evaporação dos líquidos presentes que ficaram disponíveis para serem capturados e analisados pela instrumentação GS-MS, ainda perfeitamente ativa. A resposta não deve ter sido equivocada: depois de cerca de 3 minutos, ao redor da sonda levantou-se uma autêntica nuvem de metano, etano, etileno e outros hidrocarbonetos mais pesados! De forma absolutamente inesperada, ocorreu também a obtenção de uma imagem instantânea da superfície de Titan (Figura 10), realizada por uma das três câmaras da instrumentação DISR (obviamente aquela apontada horizontalmente). Sobre o terreno, estavam disseminadas, a perder de vista, fragmentos arredondados de gelo de $10-15 \mathrm{~cm}$, erodidos na base pelo fluir de um fluido escuro e pouco viscoso: a idéia que HUYGENS tivesse pousado no fundo de um lago de metano "sujo" há pouco tempo seca (por evaporação ou dispersão do metano na profundidade do solo), pareceu absolutamente plausível. No que diz respeito ao contexto geológico geral da zona do pouso, o DISR pôde realizar imagens ópticas apenas ao sair da altitude de cerca $20 \mathrm{~km}$, porque em altitude maior a atmosfera era completamente opaca. Os primeiros mosaicos foram suficientes para nos oferecer descobertas científicas memoráveis, tão inesperadas, que roçavam o inacreditável. Entretanto ficou logo claro que os ventos empurraram HUYGENS exatamente sobre o

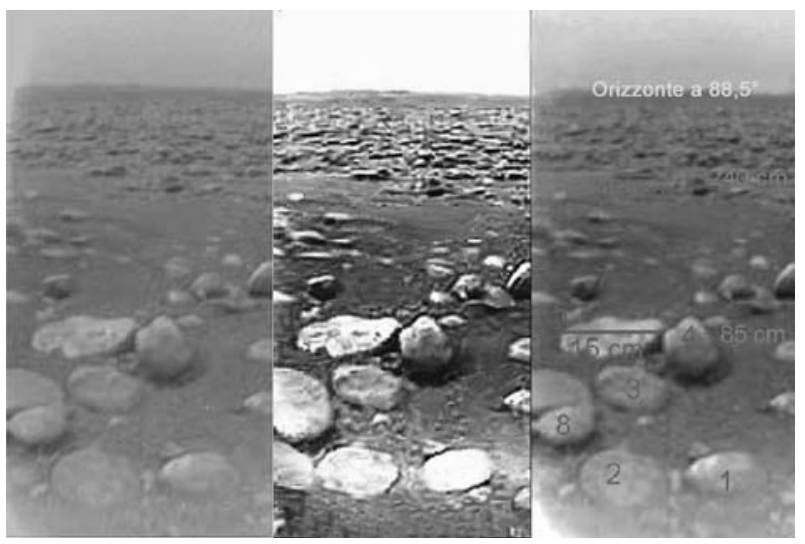

Figura 10. A primeira e única imagem da superfície de Titan, fotografada por Huygens depois do pouso. Ninguém teria imaginado que a câmara horizontal poderia nos apresentar imagens de imensa relevância científica. A superfície lacustre, local do pouso, aparece disseminada, a perder de vista, de calotas de gelo de água, arredondados na base por líquidos hidrocarbônicos que deveriam fluir muito copiosos durante a estação "úmida" tipo de superfície mais desejável como um todo, ou seja, sobre o contorno entre um terreno claro e um terreno escuro. Imediatamente o enigma desses terrenos dissolveu-se. O terreno claro revelou ser do tipo "continental" (ou seja, realçado e enrugado), enquanto que o terreno escuro, do tipo "lacustre" (ou seja, chato e encavado). Inacreditável foi como se mostrou a morfologia dos terrenos claros (Figuras 11,12 e 13): eles apareceram sulcados por uma miríade de canais escuros dendriformes, ricos de afluentes que acabavam normalmente o seu percurso "jogando-se" no vale em direção dos terrenos escuros. HUYGENS descobriu, portanto, que sobre Titan os rios realmente existem e que, seguramente, são muito mais numerosos e bizarros do que aquilo que poderíamos ter imaginado. Todos os rios, limítrofes à zona do

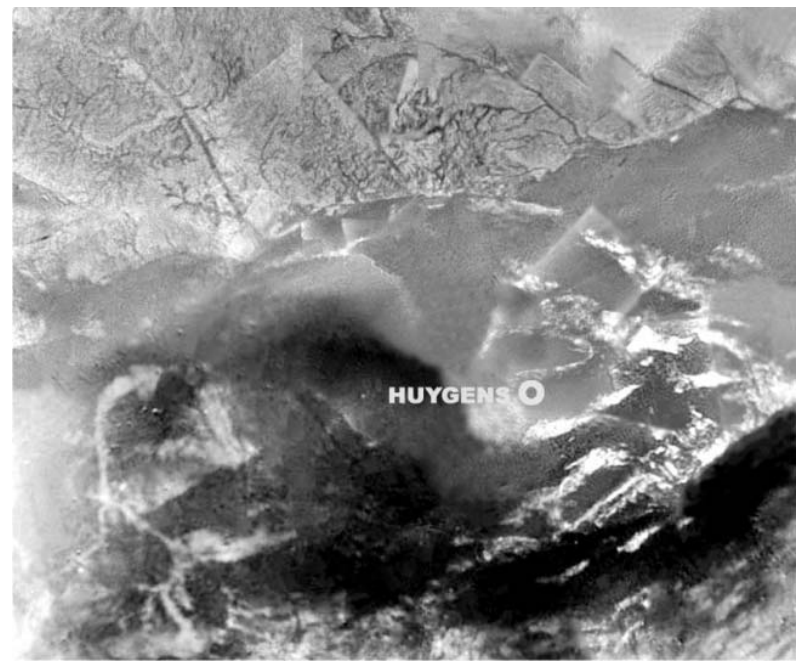

Figura 11. Este mosaico (25 km de lado) de uma trintena de imagens, fotografadas pelo DISR, entre 13 e $8 \mathrm{~km}$ sobre a superfície de Titan, fica centrado sobre o ponto de pouso da Huygens. Trata-se da superfície de um lago que ficou escuro pelo depósitos hidrocarbônicos e ponteado de ilhas brancas de gelo. As margens limítrofes ao fundo lacustre aparecem atravessadas por um inacreditável retículo de rios, nos quais provavelmente flui uma mistura de metano e hidrocarbonetos coloridos mais pesados

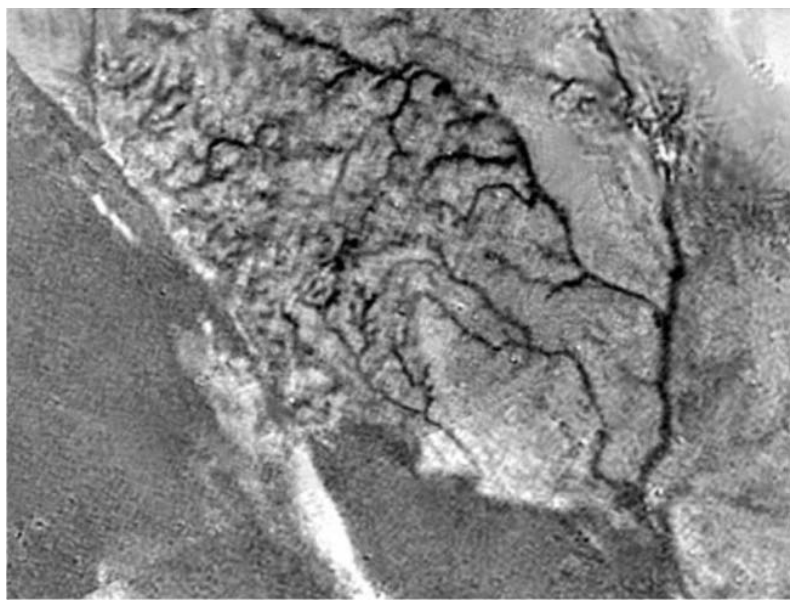

Fgura 12. Um dos rios de Titan, fotografado no momento no qual ele se joga na próxima bacia lacustre. A coloração escura do leito desses rios depende dos depósitos de hidrocarbonetos fotossintéticos erodidos pela chuva de metano. Atualmente os rios são secos, mas é provável que também ao longo do ano saturniano exista uma "estação das chuvas" 

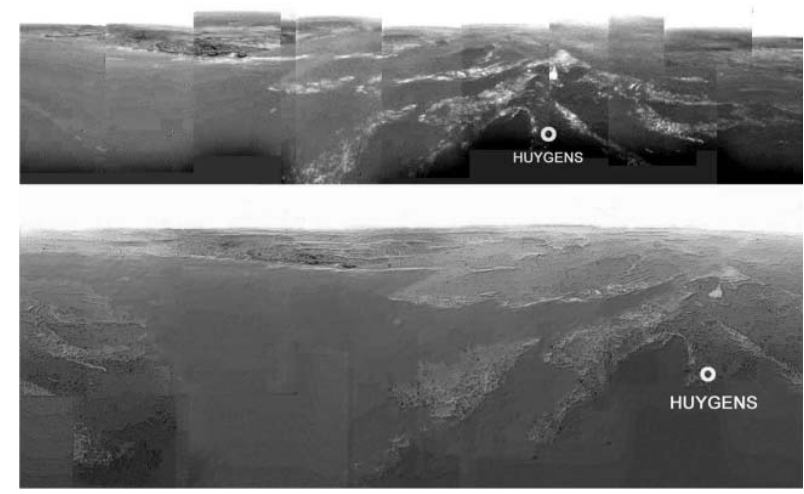

Figura 13. zona de pouso do Huygens num espetacular mosaico de $180^{\circ}$, fotografado do DISR a $8 \mathrm{~km}$ de altitude. As linhas da margem são embranquecidas por prováveis névoas de metano. A superfície lacustre em primeiro plano fica disseminada por ilhas de gelo

pouso, apresentavam nível baixo: indubitavelmente, porém, foram as recentes chuvas torrenciais de metano que os produziram. Além disso, o fato de que os leitos dos rios de Titan apareceram sistematicamente escuros permitiu imediatamente que se compreendesse, tanto a gênese desses rios, como a natureza dos terrenos escuros nos quais eles se jogam. De fato, é o próprio metano líquido um ótimo solvente para as tolinas poliméricas que se depositam em grande quantidade sobre a superfície gelada. Conseqüentemente, quando chove sobre Titan, os terrenos gelados são novamente limpos das lamas orgânicas escuras aí depositadas, retomando o aspecto claro original. O metano, ao contrário, enriquecido destes compostos, flui nos rios em forma de líquido escuro e viscoso e acaba derramando as tolinas orgânicas nele dissolvidas no fundo das bacias onde os rios desembocam. Isso significa que os "continentes" de gelo ficam sempre mais claros, enquanto as bacias lacustres ficam sempre mais escuras. Quando não "chove" por um tempo longo o metano tende a evaporar: conseqüentemente, no fundo dos rios e dos lagos a coloração fica ainda mais escura porque a porção orgânica colorida (cujo peso molecular não permite que evapore) concentra-se mais a cada dia. As imagens de HUYGENS gravadas abaixo de $8 \mathrm{~km}$ de altitude evidenciam também a presença de "ilhas" claras, isoladas ou em grupo, no interior das superfícies lacustres escuras. Trata-se de colinas de gelo com alturas de até 600 metros, muito brilhantes no cume (causado pelo efeito erosivo das chuvas de metano) e muito escuras na base, onde, durante os períodos de "cheia" impedem o fluxo dos líquidos hidrocarbônicos. A origem dessas colinas é incerta, mas uma boa hipótese é que foram geradas por fenômenos de crio vulcanismo, ou seja, da lenta emersão do gelo da água tornada mais plástica e baixo-fundente pela presença de compostos amoniacais. Isso foi confirmado por outras imagens de HUYGENS, nas quais parece discernir amplas calotas de gelo emergentes das longas e retilíneas fraturas do solo. Pode não ser por acaso que nos arredores foram visualizadas dezenas de "nascentes" escuras de metano, evidentemente postas em movimento pela sobra de calor endógeno do sub solo. Todavia, o fato do crio vulcanismo estar presente em Titan não é somente fruto de suposições, mas deriva de uma das observações mais importantes adquiridas pela instrumentação GC-MS durante a descida. Tratase da descoberta, realmente notável, da existência de ${ }^{40} \mathrm{Ar}$ (Argônio 40) na atmosfera de Titan (ainda mais significativa se considerarmos a já mencionada ausência de ${ }^{[36]} \mathrm{Ar}$ ). $\mathrm{O}^{[40]} \mathrm{Ar}$ é produzido do decaimento do ${ }^{40} \mathrm{~K}$ (Potássio 40) um dos componentes primordiais do núcleo rochoso profundo. Evidentemente, se o ${ }^{40} \mathrm{Ar}$ se encontra na atmosfera de Titan, isso significa que deve existir algum processo que o faz emergir na superfície, chegando das profundidades onde se produz.

Portanto, o crio vulcanismo não somente é possível, mas provável. Para a confirmação disso, seria necessária uma investigação prolongada na órbita de Titan em Saturno, perfurando as nuvens com um radar sintético e procurando manchas "térmicas" no infravermelho próximo a 5 mícron.

Este trabalho que a CASSINI iniciou em Fevereiro de 2005, já forneceu nos primeiros 18 meses (três sobrevôos radar em 2005 e um outro sobrevôo radar em 30 de Abril de 2006) resultados, sendo modesto, sensacionais. Em suma, longe de ser um fenômeno localizado na região onde pousou HUYGENS, a presença de rios de metano grandes e pequenos, parece disseminar-se por grande parte da superfície de Titan. Parece ainda que a superfície seja castigada por ventos violentíssimos que geram imensos campos de dunas paralelas, incrivelmente similares àquelas dos desertos terrestres. Descobertas sempre mais inesperadas e reveladoras são aguardadas por pelo menos uns vinte sobrevôos entre a CASSINI e Titan, já programados para antes do fim nominal da missão (Julho de 2007). Cresce ao mesmo tempo o empenho e o entusiasmo da ESA (Agência Espacial Européia) que olha, enfim, para Titan como um dos objetivos primários da próxima geração de cientistas planetários. A idéia é de enviar uma sonda na órbita em volta do satélite, tendo a bordo, não uma, mas muitas cápsulas similares à HUYGENS, para serem depositadas em algum dos lugares que serão escolhidos entre os mais interessantes. Em seguida, talvez, caberá diretamente ao homem completar a exploração. Uma eventualidade que, por enquanto, parece distante tanto no tempo como no espaço (Saturno e Titan estão, de qualquer maneira, a 1,5 bilhões de km da Terra), e isso será inevitável caso qualquer forma de vida for realmente descoberta naquele mundo primordial e fantástico.

\section{Referência Bibliografica}

1. Bézard, B. et al., Detection of Acetonitrile on Titan. Bull. Am. Astr. Soc., 25, 1100 (1993)

2. Bézard, B. et al. - First Ground Based Detection of Cyanoacteylene on Titan. Bull. Am. Astr. Soc., 24, 953 (1992)

3. Boone, S. \& Nicol, M. F. - Ammonia-Water Mixtures at High Pressures Revisited. Proc. Lunar. Planet. Sci. Conf., $21^{\text {st }}, 113$ (1991)

4. Broadfoot et al., Extreme UV Observations from the Voyager 1 Encounter with Saturn. Science, 212, 206 (1981)

5. Chang, J. et al. - Organic Chemistry on Titan. Rev. Geophys. Space. Phys., 17,1923 (1979) 
6. Clausen, K. \& Sainct, H. - The Huygens Probe and Mission Design. Adv. Space. Res., 14(12),189 (1994)

7. Combes, M. et al. - Titan's Near Infra-red Imaging with Adaptive Optics. Bull. Am. Astr. Soc., 29 (1997)

8. Coustenis, A. et al. - Titan's Atmosphere from Voyager Infrared Observations 1. The Gas Composition of Titan's Equatorial Region. Icarus, 80, 54 (1989a)

9. Engel, S. et al. - Cratering on Titan and Implications for Atmospheric History. Planet. Space. Sci., 43(9), 1059 (1995)

10. Elachi, C. et al. - Cassini Radar Views the Surface of Titan, Science, 308, 970 (2005)

11. Flasar, F. M. et al. - Titan's Atmospheric Temperatures, Winds, and Composition, Science, 308, 975 (2005)

12. Flasar, F. M. - Oceans on Titan? Science, 221, 55 (1983)

13. Fulchignoni. M. et al. - The Huygens Atmospheric Structure Instrument onboard the Huygens probe. International workshop Planetary Probe Atmosphere Entry and Descent Trajectory Analysis ans Science, Lisbona, 6-9 Ottobre 2003

14. Griffith, C. A. - Evidence for Surface Heterogeneity on Titan. Nature, 364, 511 (1993)

15. Griffith, C. A. et al. - Titan's Surface and Troposphere Investigated with Groundbased Near Infra-red Observations. Icarus., 93, 362 (1991)

16. Gupta, S. et al. - Organic Synthesis in the Atmosphere of Titan. Nature, 293, 725 (1981)

17. Jones, T. D. \& Lewis, J. S. - Estimated Impact Shock Production of $\mathrm{N}_{2}$ and Organic Compounds on Early Titan. Icarus, 72, 381 (1987)

18. Hunter Waite, J. et al. - Ion Neutral Mass Spectrometer Results from the First Flyby of Titan Science, 308, 982 (2005)

19. Heiko Backes, et al. - Titan's Magnetic Field Signature During the First Cassini Encounter Science, 308,: 992 (2005)

20. Khare, B. N. et al. - Amino Acids Derived from Titan Tholins. Icarus., 68, 176 (1986)

21. Khare, B. N. et al. - Molecular Analysis of Tholins Produced under Simulated Titan Conditions. Bull.Am. Astr. Soc., 14, 714 (1982)

22. Khare, B. N. et al. - The Organic Aerosols of Titan. Adv. Space. Res., 4, 59 (1984)

23. Kunde, V. G. et al. - $\mathrm{C}_{4} \mathrm{H}_{2}, \mathrm{HC}_{3} \mathrm{~N}$ and $\mathrm{C}_{2} \mathrm{~N}_{2}$ in Titan's Atmosphere. Nature., 292, 686 (1981)

24. Lebreton, J. P. - The Huygens Probe. In Proceedings of the Symposium on Titan. ESA Special Publication, 338, 287 (1992)
25. Lorenz, R. D. - Cassini Mission-Radar Sensing of Craters on Titan. Lunar. Planet. Sci. Conf., XXVI, 863 (1995)

26. Lorenz, R. D. et al. - The Life, Death, and Afterlife of a Raindrop on Titan. Planet. Space. Sci., 41(9), 647 (1993a)

27. Lorenz, R. D. - Raindrops on Titan. Adv. Space. Res., 15(3), 317 (1993b)

28. Lorenz, R. D. - Huygens Probe: The Surface Mission. In Proceedings of the Symposium on Titan. ESA Special Publication, 338, 359 (1992)

29. Lorenz, R. D. \& Zarnecki, J. C. - Precipitation on Titan and the Methane Icing Hazard to the Huygens Descent Probe. Ann. Geophys., 10(3), C487 (1992)

30. Lunine, J. L. et al. - Surface-Atmosphere Interactions on Titan Compared with those on the Pre-Biotic Earth. Adv. Space. Res., 15(3), 303 (1995)

31. Lunine, J. L. - Does Titan Have an Ocean? A Review of Current Understanding of Titan's Surface. Review of Geophysics., 31(2), 133 (1993)

32. Lunine, J. L. \& Stevenson, D. J. - Clathrate and Ammonia Hydrate at High Pressure: Application to the Origin of Methane on Titan. Icarus., 70, 61 (1987)

33. Lunine, J. L. et al. - Ethane Ocean on Titan. Science, 222, 1229 (1983)

34. Mahaffy, P. R. - Intensive Titan Exploration Begins, Science, 308,: 969 (2005)

35. Pinto, J. P. et al. - Photochemical Production of Formaldehyde in the Earth's Primitive Atmosphere. Science, 210, 183 (1980)

36. Raulin, F. - Organic Chemistry in the Oceans of Titan. Adv. Space. Res., 7(5), 71 (1987)

37. Raulin, F. et al. - Organic Synthesis from $\mathrm{CH}_{4}-\mathrm{N}_{2}$ Atmospheres: Implications for Titan.

38. Orig. Life, 12, 267 (1982)

39. Sagan, C. et al. - Production and Condensation of Organic Gases in the Atmosphere of Titan. Icarus, 59, 133 (1984)

40. Smith, P. H. et al. - Titan's Surface Revealed by HST Imagery. Icarus, 119, 336 (1996)

41. Strobel, D. F. - The Photochemistry of Hydrocarbons in the Atmosphere of Titan. Icarus, 21, 466 (1974)

42. Thompson, W. R. et al. - Production and Fate of Hydrocarbons, Nitriles, and Heteropolymers on Titan. Orig. Life. Evol. Biosphere., 19, 475 (1989)

Cesare Guaita (RHODIA Engineering Plastics) (tradução: Roberto Filippini Fantoni - AIM; cooperação: Silvio Manrich - ABPol)

Cesare Guaita é um químico macromolecular que trabalha em pesquisa na Rhodia Engineering Plastics e normalmente se ocupa de macromoléculas lineares, mas trabalhou bastante na síntese de poliamidas 6 com estrutura "a estrelas". É importante ressaltar que este tipo de trabalho parece sina do destino porque tem toda afinidade com a grande paixão do pesquisador que ele experimenta no setor da astronomia e particularmente no estúdio do sistema solar, seguindo em detalhe todas as missões das várias cápsulas enviadas ao espaço da NASA e das outras organizações espaciais. Guaita é autor de muitas publicações sobre as poliamidas, mas ao mesmo tempo publicou vários artigos astronômicos; é presidente de uma das mais importantes associações astrófilas italianas e é também um conferencista muito ativo com mais de mil conferências no Planetário de Milão e em vários outros eventos científicos em 25 anos de atividade. Recentemente publicou um livro "A procura da vida no sistema solar", de quinhentas páginas com mais de mil deslumbrantes fotos. Pedimos-lhe que falasse da aventura da descida da sonda Cassini e da cápsula Huygens e do extraordinário mundo descoberto abaixo das nuvens de Titan (um dos mais estudados satélites de Saturno) onde, apesar das baixíssimas temperaturas, se encontram não somente lagos de metano e vários hidrocarbonetos, mas também polímeros baixa massa molar e copolímeros hidrocarbônicos que se sintetizaram no curso dos séculos, mesmo naquelas condições "impossíveis". Para os estudiosos de polímeros trata-se de uma aventura extremamente intrigante. 


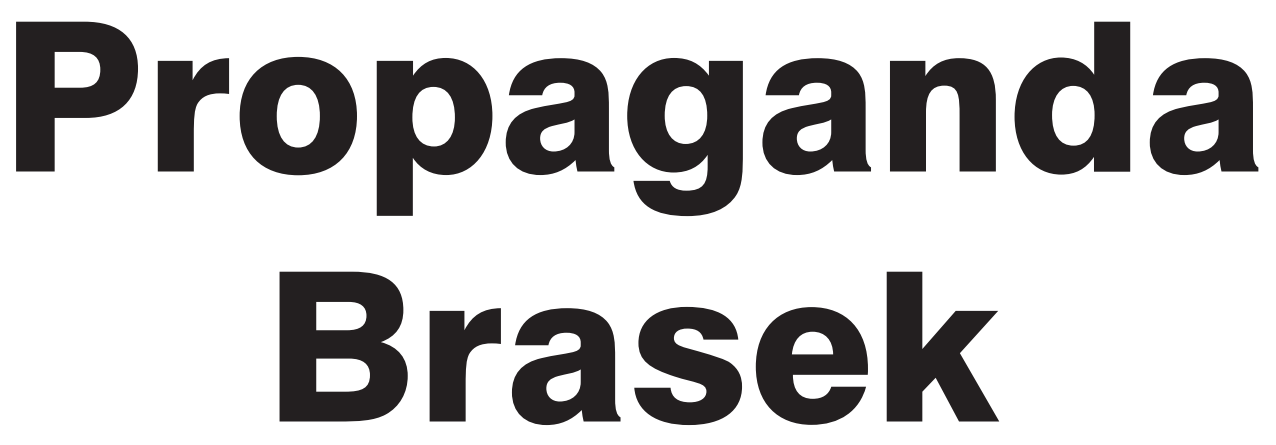

